\title{
WAVE RUN-UP OBSERVATIONS ON REVETMENTS WITH DIFFERENT POROSITIES
}

\author{
Stefan Schimmels ${ }^{1}$, Michalis Vousdoukas ${ }^{1}$, Dagmara Wziatek ${ }^{1}$, Katharina Becker ${ }^{1}$, \\ Fabian Gier $^{2}$ and Hocine Oumeraci ${ }^{3}$
}

\begin{abstract}
Wave run-up plays an important role in the design of coastal protection structures. However, none of the existing formulae for wave run-up predictions explicitly considers the effect of revetment porosity. Recently, two revetments have been tested in the Large Wave Flume (GWK) of Forschungszentrum Küste (FZK), a new type of highly porous polyurethane bonded (PBA revetment) revetment and a smooth interlocked pattern placed concrete block revetment (IPPB revetment), which is considered as "weakly permeable" for the present study. Wave run-up is evaluated by video data analysis based on timestack image processing. The results derived from the timestacks are compared to run-up data measured with conventional wire gauges and the good agreement demonstrates the accuracy and reliability of the video data analysis. The effect of the porosity of the revetment is incorporated into the EuroTop wave run-up formula, showing that for the present case it may reduce the relative run-up heights $R_{\mathrm{u}, 2 \%} / H_{\mathrm{m} 0}$ by about $25 \%$ to $50 \%$ as compared to a smooth impermeable slope.
\end{abstract}

Keywords: Porous Revetment, Wave Run-Up, Video Data Analysis, Large Scale Model Tests

\section{INTRODUCTION}

Wave run-up is presumably one of the most crucial aspects in the design of sea dikes and other coastal defense structures. It naturally determines the crest height of a dike and can have a significant influence on the stability of a permeable revetment. In terms of coastal protection it is therefore desirable to reduce the wave run-up as much as possible, e.g. by increasing the porosity of the dike revetment. The porosity can reduce wave run-up height in two ways: (i) by reducing the swash water volume through infiltration and (ii) by the turbulent dissipation of wave energy inside the revetment.

For design purposes it is desirable to theoretically predict wave run-up heights and several empirical formulae based on laboratory or field data were suggested in the past. Although there are differences in these equations it is generally accepted that wave run-up mostly depends on wave height, wave period or length, respectively, and the slope of the beach or structure. One of the earliest parameterizations for wave run-up by Hunt (1959) is given by

$$
\frac{R}{H_{0}}=\xi=\frac{\tan \alpha}{\sqrt{H_{0} / L_{0}}}
$$

where $H_{0}$ and $L_{0}$ are the deep water wave height and length and $\tan \alpha$ is the slope. It suggests the relative run-up height to directly depend on the surf similarity parameter or Iribarren number $\xi$ (Battjes, 1974; Iribarren and Nogales, 1949), which relates the slope to the wave steepness $H / L$.

For regular waves equation (1) is well defined, however, for irregular waves a unique definition of run-up height, wave height and wave length leaves some space for discussion. The former has been generally agreed upon to be $R_{\mathrm{u}, 2 \%}$, the wave run-up height which is exceeded by $2 \%$ of the total number of incoming waves. The wave height is usually given by the significant wave height $H_{\mathrm{m} 0}$ and the wave length by $L_{\mathrm{m}-1,0}$, the wave length corresponding to the mean wave period $T_{\mathrm{m}-1,0}$, defined by $\mathrm{m}_{-1} / \mathrm{m}_{0}$, the $-1^{\text {st }}$ and $0^{\text {th }}$ moment of the wave spectrum.

After Hunt (1959) several other formulations combining $H$ and $L$ in different ways have been suggested for natural slopes like beaches, (Holman, 1986; Synolakis, 1987; Mase, 1989; Nielsen, 1989; Ruggiero et al., 2004; Stockdon et al., 2006; Vousdoukas et al., 2009; Vousdoukas et al., 2012). However, all these formulations only take the wave parameters and the slope itself into account, neglecting other influencing factors like friction or porosity. For coastal structures like breakwaters and dikes a more general formulation is suggested in EuroTop (2007), which considers the effect of berms, roughness or angle of wave attack:

$$
\frac{R_{2 \%}}{H_{\mathrm{m} 0}}=c_{1} \cdot \gamma_{b} \cdot \gamma_{f} \cdot \gamma_{\beta} \cdot \xi_{\mathrm{m}-1,0} \quad \text { with a maximum of } \frac{R_{2 \%}}{H_{\mathrm{m} 0}}=\gamma_{f} \cdot \gamma_{\beta} \cdot\left(c_{2}-\frac{c_{3}}{\sqrt{\xi_{\mathrm{m}-1,0}}}\right)
$$

\footnotetext{
1 Forschungszentrum Küste (FZK), Merkurstr. 11, 30419 Hannover, Germany

2 Institute of Hydraulic Engineering and Water Resources Management, RWTH Aachen, Mies-van-der-Rohe-Str. 1, 52056 Aachen, Germany

3 Leichtweiss-Institute for Hydraulic Engineering and Water Resources, Technische Universität Braunschweig, Beethovenstr. 51a, 38106 Braunschweig, Germany
} 
The empirical nature of equation (2) becomes obvious as the "classical" linear relation between the relative run-up height and the surf similarity parameter is limited by the expression on the right, which was found by data fitting. The fitting parameters $c_{1}, c_{2}$, and $c_{3}$ are suggested in EuroTop (2007) to take values of $c_{1}=1.65, c_{2}=4.0$ and $c_{3}=1.5$ and parameters $\gamma_{\beta}, \gamma_{b}$ and $\gamma_{f}$, serve to account for angle of wave attack, berms and friction, respectively and take a value of 1.0 for a smooth impermeable and uniform slope under perpendicular wave attack.

The present study sets out to discuss the influence of porosity on wave run-up by the example of two data sets which have been recently obtained during large scale experiments at the Large Wave Flume (Großer Wellenkanal, GWK) of Forschungszentrum Küste (FZK), Hannover, Germany. A new type of highly porous polyurethane bonded aggregate revetment, called hereafter PBA revetment was extensively tested 2009-2010 in GWK with regards to the hydraulic performance, the wave loading on and in the soil beneath the revetment (Oumeraci et al., 2010, Oumeraci et al, 2012). About one year later 2010-2011 the stability of a smooth interlocked pattern placed concrete block revetments, called hereafter IPPB revetment, was also tested in the large wave flume . Although the IPPB revetment tests were actually not focused on wave run-up, the data are also considered for the present study. Due to the joints between the individual concrete blocks this type of revetment is slightly permeable (about $3 \%$ porosity) and can be interpreted as being representative for a weakly "porous" revetment. Moreover, the sizes of the crushed stones of the PBA revetment are so small $(16 / 36 \mathrm{~mm})$ that the effect of the surface roughness on the revetment on the wave run up can be neglected.

By default both experiments were documented with video recordings, which have now been processed for wave run-up by time stack image analysis. In addition for the PBA revetment experiments, wave run-up was measured with conventional wire gauges. The data has been re-analyzed and serves as a reference for comparison with the automated video data analysis.

The model set-up for the experiments and the analysis technique for the video data based on time stack images will be described in the following. After that the run-up time series from the wire gauges and the video data (PBA revetment only) will be compared and interpreted. Finally, the relative run-up heights $R_{\mathrm{u}, 2 \%} / H_{\mathrm{m} 0}$ will be presented and discussed for both revetments and a new parameter to account for porosity is suggested. Further results on wave loads on and beneath the PBA and IPPB revetments, as well as on the effect of porosity are presented by Liebisch et al (2012) and Gier et al. (2012).

\section{MODEL SET-UP}

Both experiments were performed on a 1:3 slope, which was installed at the end of the flume. At the toe of the slope there was a $1 \mathrm{~m}$ high foreshore with a slope of 1:20 and the slope crest was at about $6.70 \mathrm{~m}$ height. The average still water depth was $4.5 \mathrm{~m}$ for all tests during the IPPB experiments and $4 \mathrm{~m}$ for the PBA revetment experiments, where the depth was slightly altered for each test in order to adjust the breaking point of the waves. A sketch of the general model set-up for both experiments is shown in Figure 1.

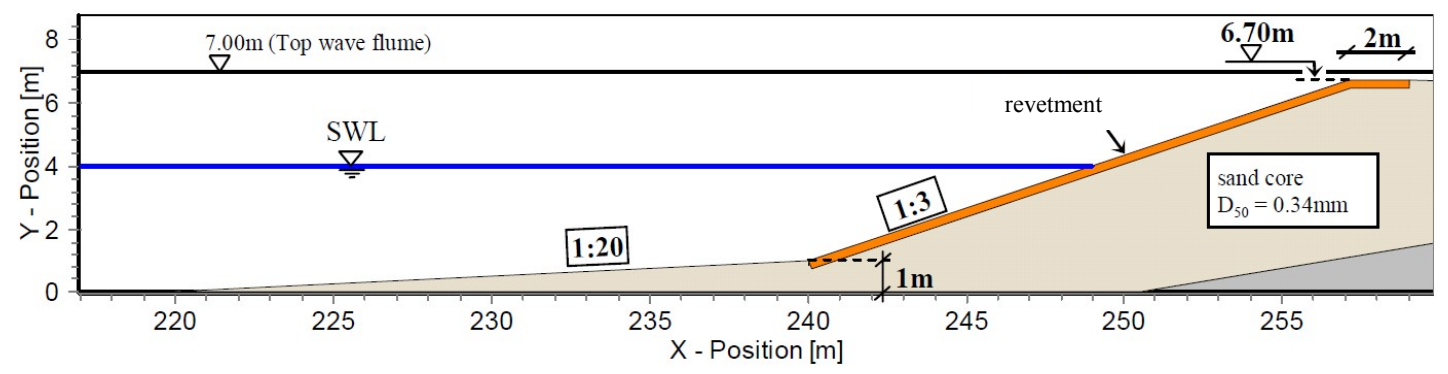

Figure 1. Model set-up for PBA revetment and IPPB revetment experiments in GWK.

In the middle axis of the slope a separation wall was installed in order to test two different revetment set-ups at the same time (cf. Figure 6). In the PBA revetment three different set-ups were investigated, i.e. one side was changed once. However, the present study is focused on the data obtained for two revetment set-ups, Model B and Model C only, which are sketched in Figure 2.

In Model $B$ a $15 \mathrm{~cm}$ bonded limestone layer with a mean grain size of $d_{50} \approx 4 \mathrm{~cm}$ was placed on a $10 \mathrm{~cm}$ non-bonded filter layer of the same material. For Model $C$ the bonded revetment layer had also a thickness of $15 \mathrm{~cm}$, but the limestone was replaced by granite. However, the mean grain size remained at $d_{50} \approx 4 \mathrm{~cm}$ and the major difference between both set-ups is the thickness of the filter layer, which was increased to $20 \mathrm{~cm}$. 

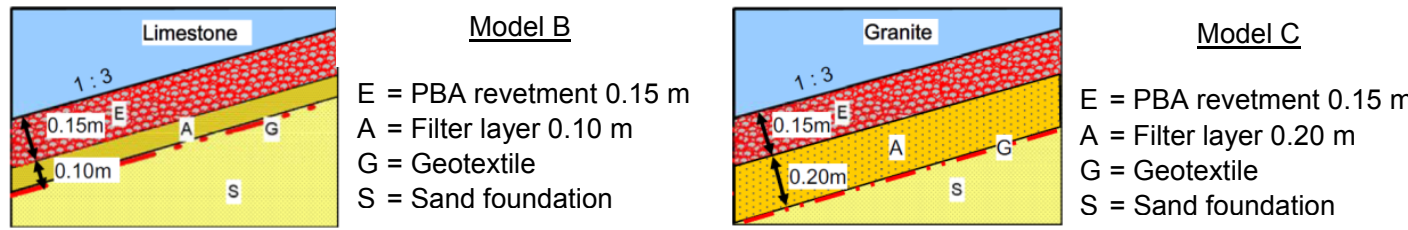

Figure 2. Two different set-ups with PBA revetment; left: "Model B", right: "Model C"

In the IPPB revetment experiments five different concrete blocks were investigated. The stones were placed on a $10 \mathrm{~cm}$ filter layer which was separated from the sand core by a geotextile. Figure 3 shows the individual block types which are all considered for the present study.
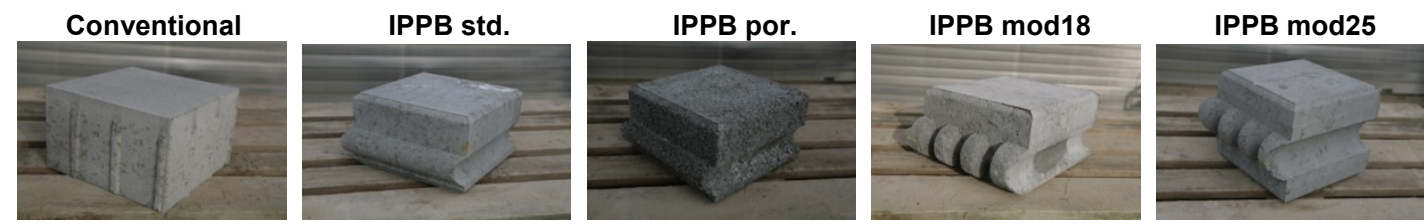

Figure 3. Different types of revetment stones tested in IPPB revetment experiments

The Conventional block is a simple non-interlocked revetment stone, frequently used in practice. $I P P B$ std. represents the standard shape for the interlocked stones with a continuous slot and key system at the sides and a typical size of $30 \mathrm{~cm} \times 30 \mathrm{~cm} \times 18 \mathrm{~cm}$, just as that of the non-interlocked Conventional block. IPPB por. has exactly the same shape and size as the standard stone, but it is made with a different type of concrete such that the surface of the stone is porous, but the whole block itself still remains impermeable. IPPB $\bmod 18$ also has the same size like the standard stone, but a modified slot key system with a continuous slot and an interrupted key. IPPB $\bmod 25$, finally, is similar to IPPB $\bmod 18$, but instead of $18 \mathrm{~cm}$, as for all the other stones, the stone height is $25 \mathrm{~cm}$.

The definition of porosity is straightforward for the PBA revetment, because the crushed stones are actually only bonded at the contact planes, i.e. the porosity of the original material is not altered and corresponds to that of the non-bonded filter layer, which is of the same material. Figure 4 shows some detailed pictures of the PBA revetment.
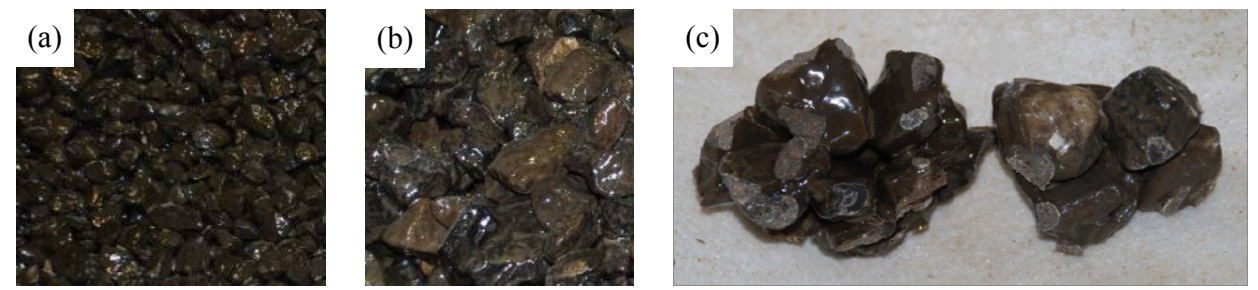

Figure 4. Pictures of PBA revetment; (a) and (b) bonded crushed stones; (c) contact planes.

To define the IPPB revetment as being ,porous“ is actually not fully correct, as the concrete blocks themselves are impermeable. However, due to the joints between the individual concrete blocks the entire revetment is slightly permeable and it is considered here as being representative for a weakly „porous" revetment. Figure 5 shows a sketch of the joint between two stones and a sketch of the IPPB modl18 stone, which is supposed to be slightly more "porous" due to the non-continuous key.
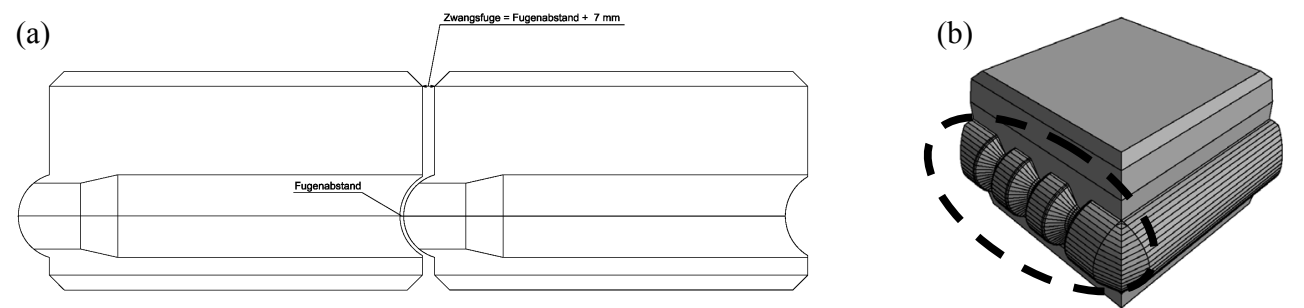

Figure 5. Sketches of IPPB revetment; (a) joint between two stones; (b) non-continuous key as for IPPB mod18 and IPPB mod25. 
The final model setup for both experiments is shown by two snapshots from the video footage in Figure 6 with the PBA experiments on the left and the IPPB experiments on the right. The video data was synchronized with the other data by a digital clock, which is visible on top of the images. The separation wall in the middle of the slopes separates the different revetment set-ups on which markers have been drawn for a visual analysis of the video data. In the PBA revetment experiments classical run-up wire gauges were installed on either side of the separation wall, which will shortly be discussed below. The red lines indicate the transects along which the video data is evaluated for the subsequent time stack analysis to be described in the next section.
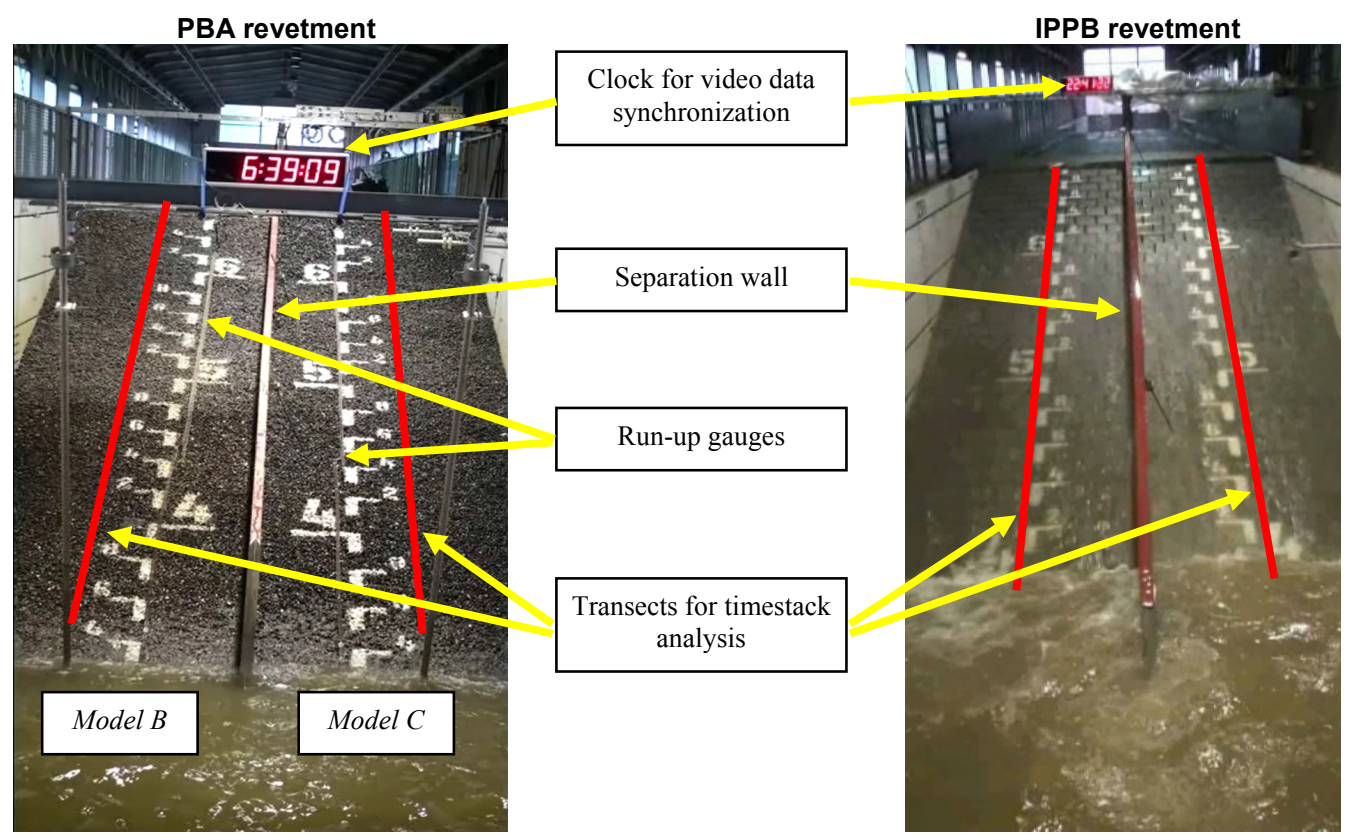

Figure 6. Snapshot from video footage with transects for video data analysis shown in red; left: PBA revetment, right: IPPB revetment

The run-up gauges in the PBA revetment experiments were resistive wire gauges with the measuring wire being surrounded by a steel grid which was fixed on the slope (Figure 7). This means that the actual run-up is not measured directly on the slope surface, but a few centimeters above, which should be kept in mind for the later comparison of the gauge measurements with the video data. Moreover, the run-up gauges had to be split up into an upper and a lower gauge for technical reasons with the transition being at about $4.4 \mathrm{~m}$ height, as shown in Figure $7 \mathrm{~b}$. This should also be kept in mind, as in a previous analysis (Oumeraci et al., 2010 \& 2012) some issues with the upper gauge were found and for cases in which this gauge was active run-up had to be determined by visual analysis of the video footage.
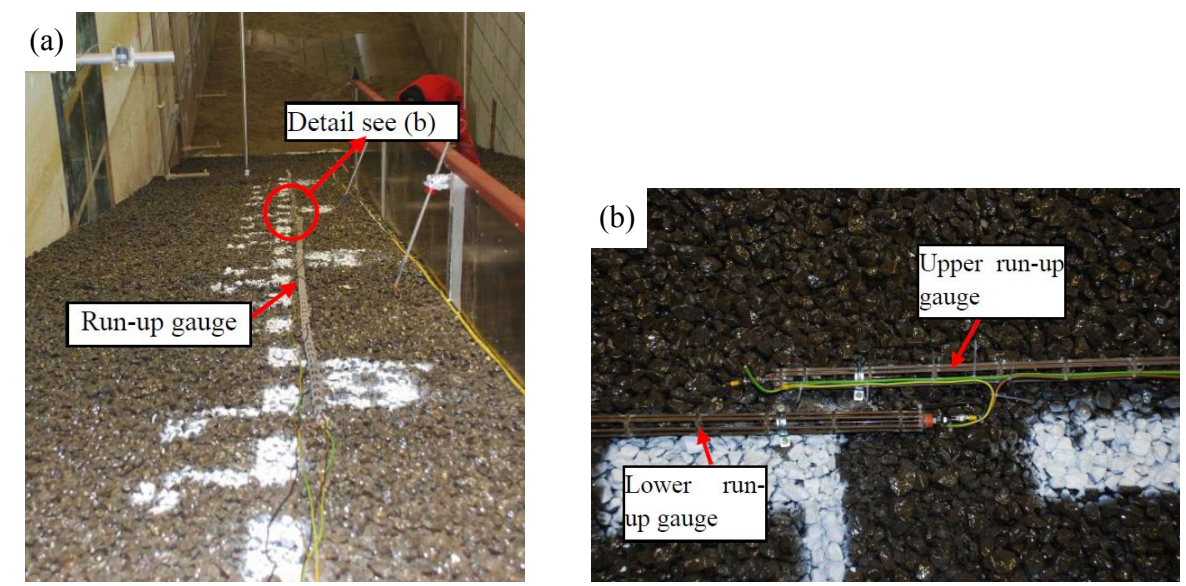

Figure 7. Detail of the transition between upper and lower run-up gauge on the slope at about $4.4 \mathrm{~m}$ height. 


\section{VIDEO DATA ANALYSIS}

The video footage which was taken during the experiments was originally only intended for documentation and partial visual analysis for reference. Therefore, only a commercial CCD video camera was used and the set-up was not optimized for automatic image analysis. Nevertheless, for the present analysis the quality of the data was sufficient to give reasonable results after applying some image enhancement.

From the video sequences at 25 fps timestack images (Aagaard and Holm, 1989) were generated by sampling pixel intensities along the predefined transects on the revetment (red lines in Figure 6), sub-sampling the video information at $5 \mathrm{fps}$. Conversion from pixel to metric dimensions was based on the markers on the revetment (see Figure 6), giving equally-spaced horizontal intervals of $60 \mathrm{~cm}$ along the transect. Image acquisition was synchronized with the other measuring devices by including a digital timer, displaying the Central Control Unit time; as a result the synchronization error was lower than the video time step, i.e. $<1 / 25$ s. Figure 8 shows the individual steps of the timestack image analysis.
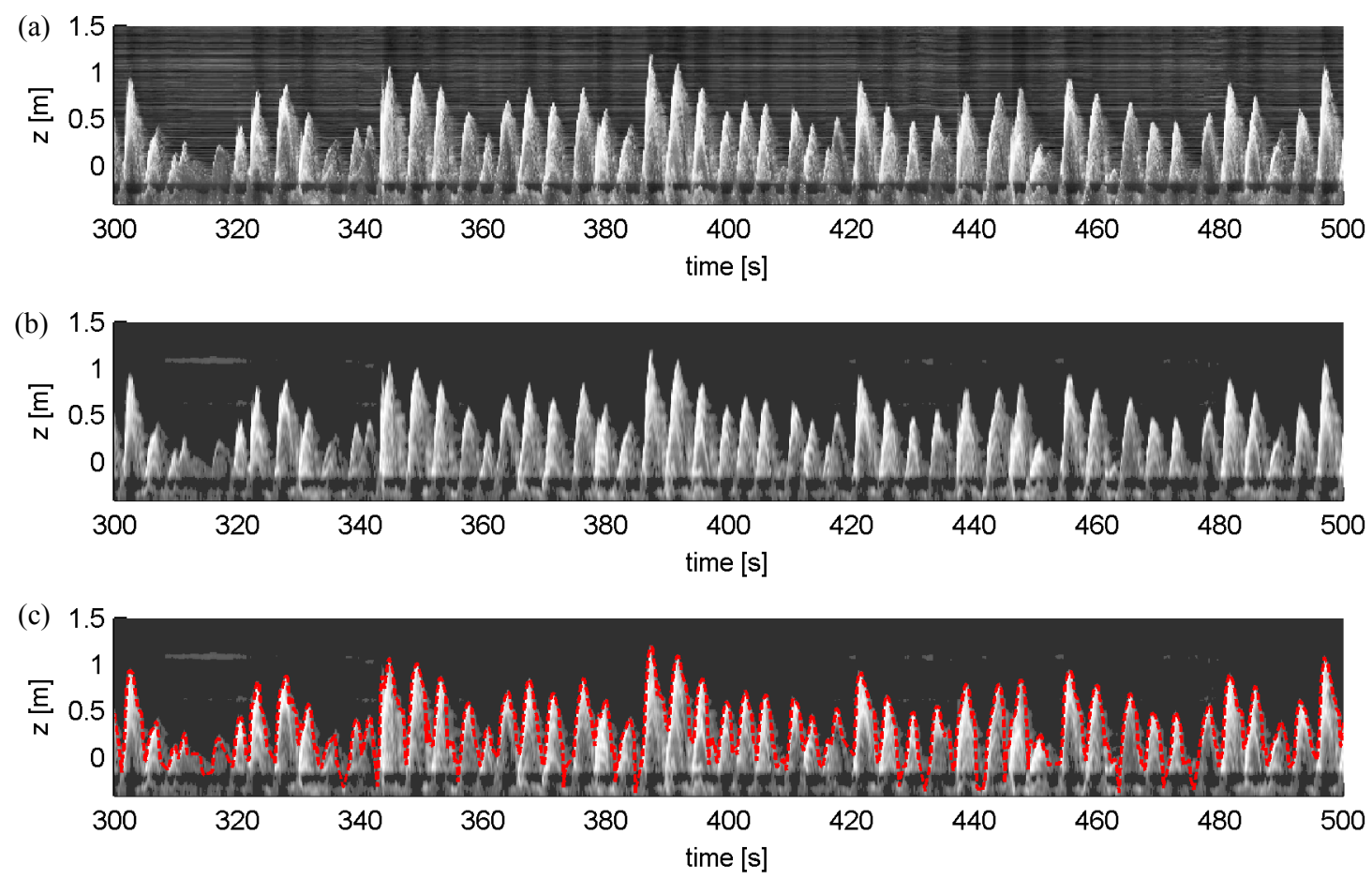

Figure 8. Individual steps for timestack image analysis; (a) original timestack image, (b) enhanced image, (c) extracted run-up time series.

The upper panel displays the original timestack image in metric dimensions, where the vertical axis represents the run-up height and $\mathrm{z}=0 \mathrm{~m}$ corresponds to the still water level. From this image the excursion of the shoreline can already quite well be identified visually, however there are still some artifacts in the upper dry region, which complicate an automated detection. Therefore the image is enhanced by a low pass filter and a threshold criterion resulting in the timestack displayed in the middle panel. From this image a wave run-up time series can be extracted accurately using a modified Otsu threshold method (Otsu, 1979). The result, shown as a red dashed line in the lower panel, can then be used for further analysis.

For the present study all timestack images were processed and analyzed with an open-access Graphical User Interface (GUI) software developed in Matlab ${ }^{\circledR}$. A snapshot of the GUI is shown in Figure 9 where the main window shows a timestack image with the redline line indicating the extracted run-up time series and the yellow dots representing the discrete maxima from which $R_{\mathrm{u}, 2 \%}$ values can be obtained. Please note that the vertical axis is upside down, i.e. maxima appear as minima in the plot. The software is able to handle several timestack images very efficiently and offers several features for the enhancement and analysis of the extracted time series. The GUI can be downloaded under https://sourceforge.net/projects/guitimestack and more information about the features of the software can also be found in Vousdoukas et al (2012). 


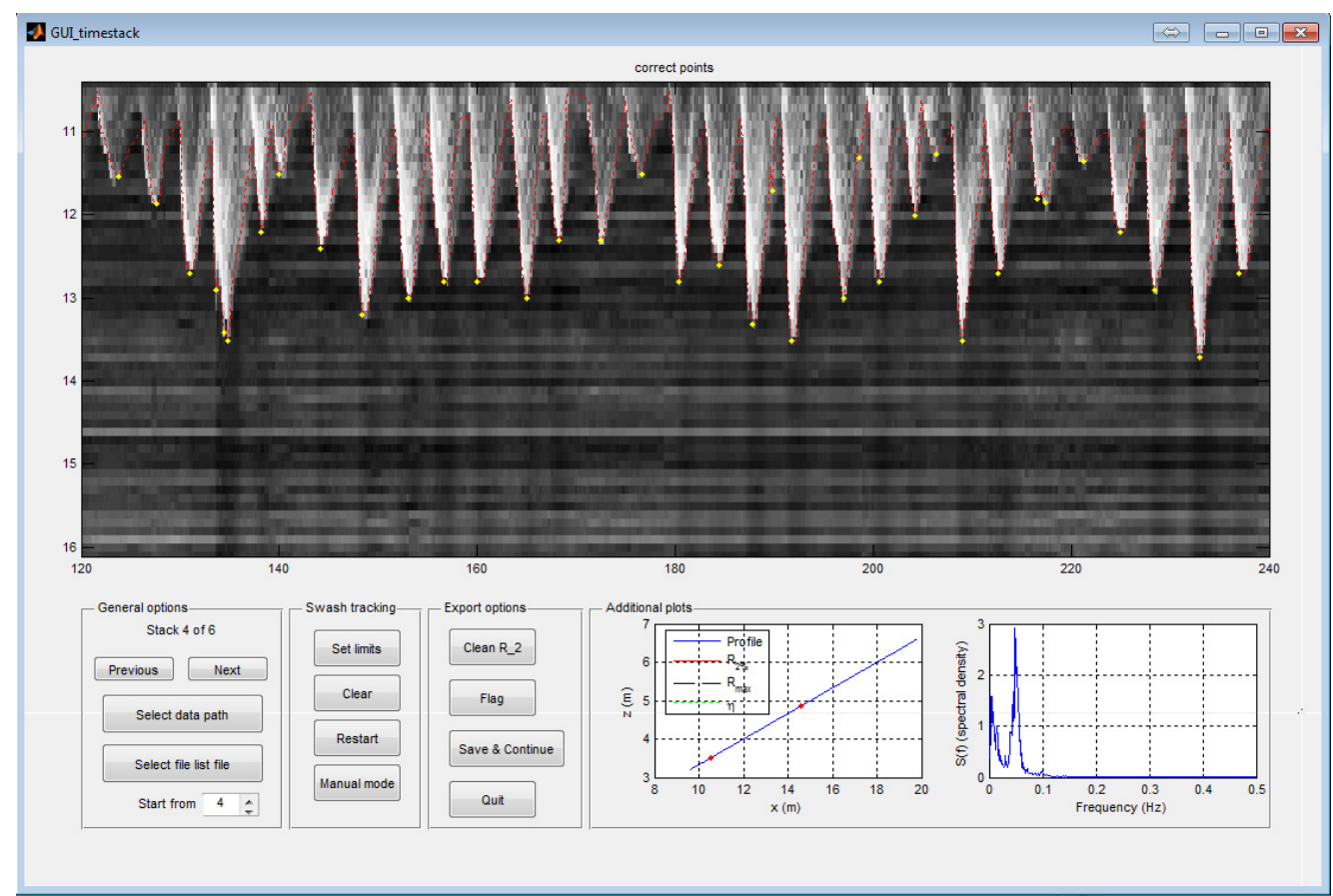

Figure 9. Snapshot of the GUI application to process timestack images.

\section{RESULTS}

\section{Experimental programs}

The main objective of the PBA revetment tests in GWK was to investigate the general performance of this new type of revetment, including wave reflection, wave run-up and run-down, wave loads on and beneath the revetments as well as the dynamic response of the structure and its foundation, while the focus of the IPPB experiments was on the stability of the interlocked stones. In both experiments several tests with regular and irregular waves were performed. However, for the present study only the irregular wave tests are considered. Figure 10 shows histograms of the corresponding wave parameters.

PBA experiments
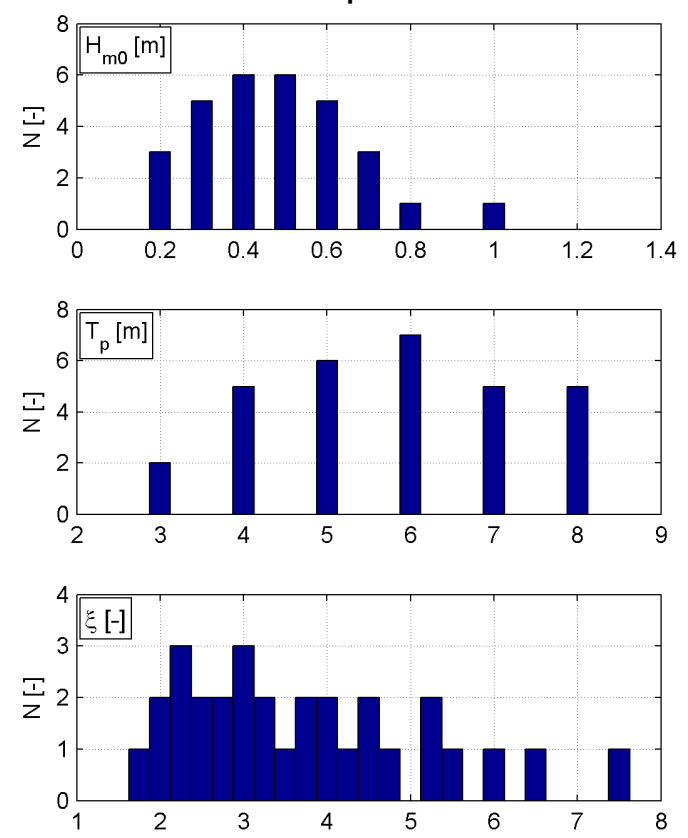

IPPB experiments
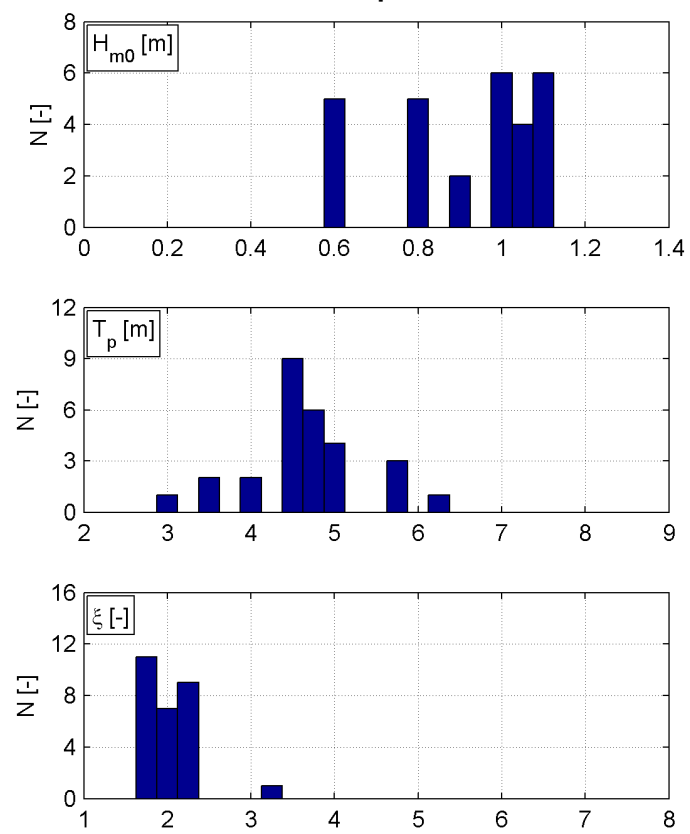

Figure 10. Histograms of the wave parameters covered by the tests on PBA revetment (left) and IPPB revetment (right) experiments; top panel: significant wave height, middle panel: peak period, bottom panel: surf-similarity parameter. 
For the highly porous PBA revetment a total of 33 and for the weakly permeable IPPB revetment a total of 28 different sea states of JONSWAP type are considered for the present analysis. The different objectives of the two experiments can be clearly deduced from the wave parameters, while the PBA revetment experiments were focused on intermediate conditions with significant wave height ranging between $0.2 \mathrm{~m}<H_{\mathrm{m} 0}<1.0 \mathrm{~m}$ and peak period ranging between $3 \mathrm{~s}<T_{\mathrm{p}}<8 \mathrm{~s}$, the major emphasis in the IPPB revetment experiments was on extreme wave conditions leading to impact loads, i.e. steeper waves, with significant wave height ranging between $0.6 \mathrm{~m}<H_{\mathrm{m} 0}<1.1 \mathrm{~m}$ and peak period ranging between $3.1 \mathrm{~s}<T_{\mathrm{p}}<6.2 \mathrm{~s}$. It should be mentioned that actually more tests were performed during the experiments, but since the present aim is to study run-up heights, only the cases without overtopping have been considered here.

The biggest difference between both datasets is the surf-similarity parameter, which for the PBA revetment experiments has quite a wide range between $1.77<\xi<7.44$, while for the IPPB revetment experiments it is basically restricted to a range of $1.67<\xi<2.35$ with one test at $\xi=3.33$, which, however, has been neglected in the later analysis. The surf-similarity parameter is quite important in terms of estimating a parameter to account for porosity in wave run-up prediction formulae, as it is the determinant quantity for run-up (cf. eq. (1) and eq. (2)). This means, for the PBA revetment a consistent curve fit through the data can be expected, but for the IPPB revetment actually more data would be needed to make a reliable parameterization for porosity. However, although the range of $\xi$ was rather limited, also the IPPB data allowed for a reasonable curve fit, but before proceeding with the run-up parameterization the new results of the video data analysis shall be compared to the measurements with the wave run-up gauges (PBA revetment tests only).

\section{Comparison of video data analysis and run-up gauges}

Exemplarily Figure 11 shows a case for $\xi=5.32$ with significant wave height $H_{\mathrm{m} 0}=0.3 \mathrm{~m}$, peak period $T_{\mathrm{p}}=7 \mathrm{~s}$ at a water depth of $h=3.5 \mathrm{~m}$. The left panel displays a part of the time series of shoreline excursion, i.e. run-up and run-down around the still water level at $\eta=0$. The red curve corresponds to the gauge measurements and the blue curve to the results from the timestack image analysis. The dots mark the individual maximum run-up values which are evaluated in the other two panels. In the middle panel all maximum run-up events for this case are compared with the results from the gauge measurements on the $\mathrm{x}$-axis and the results from the video data on the $\mathrm{y}$-axis. The right panel eventually shows the histogram of maximum run-up differences between video and gauge data.
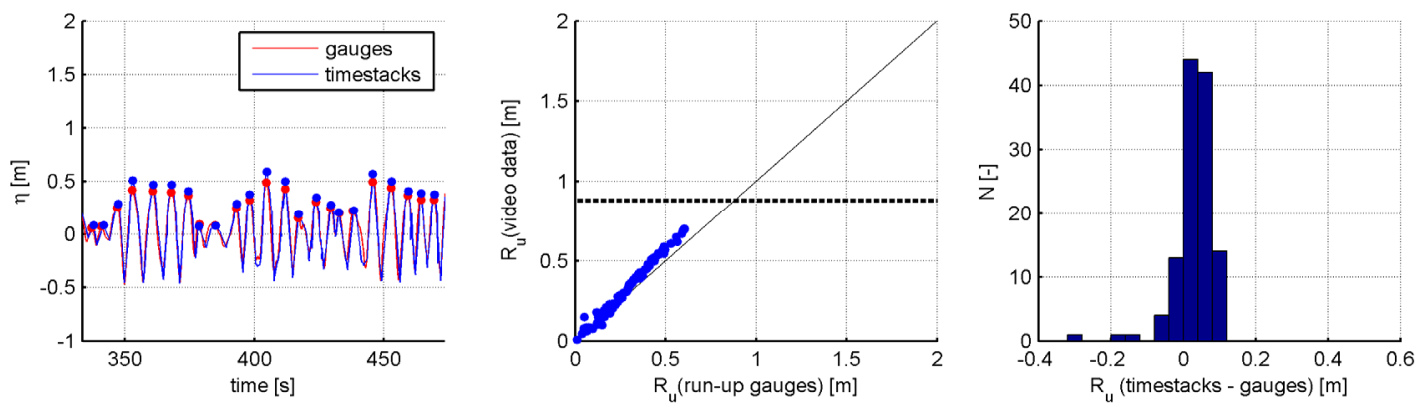

Figure 11. Comparison of wire gauge measurements and video data analysis of wave run-up for test with $H_{\mathrm{m} 0}=0.3 \mathrm{~m}, T_{\mathrm{p}}=7 \mathrm{~s}$ at $h=3.5 \mathrm{~m}$; left panel: shoreline excursion time series, middle panel: correlation of run-up values, right panel: histogram of maximum run up differences

The general agreement of the time series is obvious, although the dots indicate that the video data predicts slightly higher maximum run-up values. This is approved by the histogram plot, which has its peak around zero with a slight tendency to higher values for the timestack data. From the correlation plot it can be seen that for the rather lower run-up events the correlation between video and gauge data is very good and slight deviations begin to occur for run-up above about $30 \mathrm{~cm}$ with the tendency to a constant difference of slightly more than $5 \mathrm{~cm}$ higher values for the video data.

This rather small difference might be attributed to both, the accuracy of the gauge measurements as well as the accuracy of the video data analysis. For instance the run-up gauges require a certain amount of water around the wire in order to give a proper signal and moreover the wire itself is some few centimeters above the actual revetment surface. Therefore, when the uprushing water layer becomes very thin at maximum run-up this measurement technique is at its limit and the actual maximum value is very likely to be underestimated, just as indicated by the data in Figure 11. On the other hand also the video data has inherent uncertaintiesis and is surely not absolutely correct. With increasing distance 
from the camera the pixel size increases, too, naturally leading to a decreasing accuracy of the image processing. Furthermore, the transformation from pixel to metric units always introduces some kind of error, which might not be neglected especially for the present case, where no efforts in the set-up have been made to reduce this error. Considering these aspects a few centimeters deviation between both measurements can be regarded as a very good result.

Nevertheless, the bold, dashed line in the correlation plot in the middle panel of Figure 11 indicates the transition between the two run-up gauges at $R_{u}=0.9 \mathrm{~m}(4.4 \mathrm{~m}-3.5 \mathrm{~m})$. As all run-up values lie below that line the comparison so far was only between the video data analysis and the lower gauge. However, the example discussed above is representative for all cases where only the lower gauge was measuring. A comparison between video data and the upper gauge is shown in Figure 12.
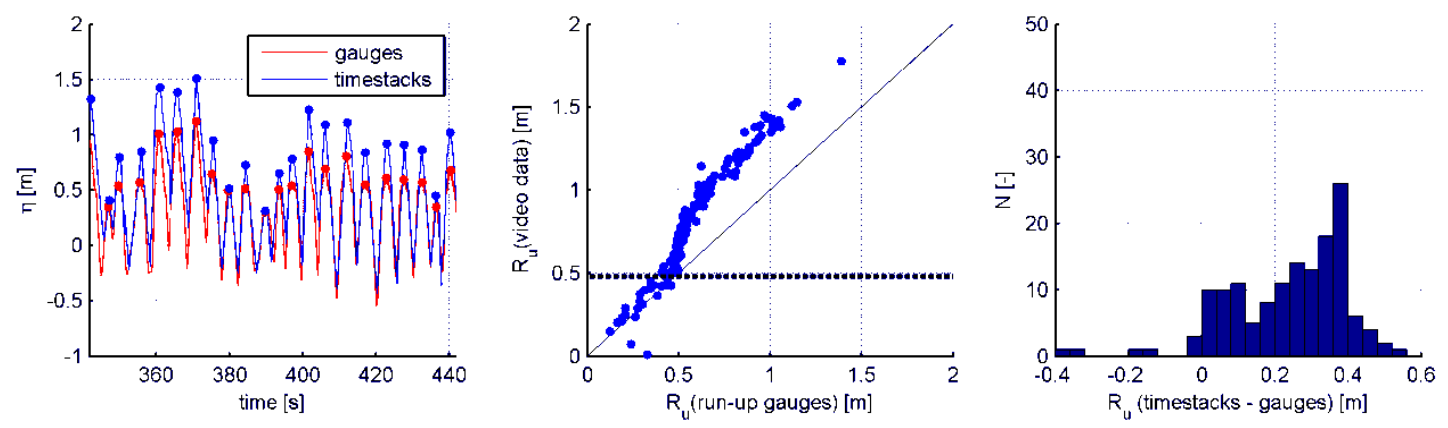

Figure 12. Comparison of wire gauge measurements and video data analysis of wave run-up for test with $H_{\mathrm{m} 0}=0.8 \mathrm{~m}, T_{\mathrm{p}}=5 \mathrm{~s}$ at $h=3.9 \mathrm{~m}$; left panel: shoreline excursion time series, middle panel: correlation of run-up values, right panel: histogram of maximum run up differences

For the considered case with significant wave height $H_{\mathrm{m} 0}=0.8 \mathrm{~m}$, peak period $T_{\mathrm{p}}=5 \mathrm{~s}$ at a water depth of $h=3.9 \mathrm{~m}$ wave run-up is generally higher and the transition between upper and lower gauge is only $50 \mathrm{~cm}$ above SWL. Therefore the lower gauge was fully inundated most of the time and the majority of run-up events was captured by the upper gauge.

From the time series in the left panel of Figure 12 it can be deduced that below $\eta=0.5 \mathrm{~m}$ where the lower gauge was active the agreement with the results from timestack image analysis is expectedly good, but for $\eta>0.5 \mathrm{~m}$ the measurements from the upper gauge show significantly lower run-up than predicted by the video data. This is confirmed by the histogram and correlation plot, which indicate that the upper gauge seems not to have properly measured in its lower part resulting in a constant shift of about $40 \mathrm{~cm}$ compared to the video data. The scientists working on the PBA project confirmed by personal communication that there was in fact an unresolved issue with the upper run-up gauges and for those cases visual analysis of the video footage had to be used to determine $R_{\mathrm{u}, 2 \%}$ values for parameterization of the effect of porosity on wave run-up to be discussed in the following.

\section{Effect of porosity on wave run-up}

The good agreement of the results from the timestack image analysis and the measurements of the lower run-up gauge as well as the fact that the shift of the upper gauge results is constant give reason to believe that the present video data analysis provides very reliable results. Therefore, a parameterization of the effect of porosity in wave run-up prediction formulae based on this data set can be expected to give reasonable results as well.

As mentioned above the state-of-the-art run-up prediction formula for dikes and coastal structures is the one suggested in EuroTop (2007), which should therefore be used here as well, but in a slightly modified way to account for the porosity. In the present case the slope has no berm, the wave attack is perpendicular and both revetments are considered as relatively smooth, so that parameters $\gamma_{b}, \gamma_{\beta}$ and $\gamma_{f}$. are equally 1.0 and can therefore be ignored. Parameters $c_{1}, c_{2}$ and $c_{3}$ are kept as suggested and the effect of porosity will be recognized by parameter $\gamma_{p}$. Hence, equation (2) can be written as

$$
\frac{R_{u, 2 \%}}{H_{\mathrm{m} 0}}=\gamma_{p} \cdot\left[1.65 \cdot \xi_{\mathrm{m}-1,0}\right] \quad \text { with a maximum of } \frac{R_{u, 2 \%}}{H_{\mathrm{m} 0}}=A \cdot \gamma_{p} \cdot\left[4.0-\frac{1.5}{\sqrt{\xi_{\mathrm{m}-1,0}}}\right]
$$


where another parameter $A$ has been introduced in order not to modify the standard empirical parameters $c_{1}, c_{2}$ and $c_{3}$ as proposed by EuroTop (2007). It is obvious that for a smooth, impermeable and uniform slope under perpendicular wave attack, which serves as the reference case, the parameters $\gamma_{p}$ and $A$ are 1.0 equally.

For the porous revetments considered here the parameters are determined by least square fitting of equation (3) through the measurement data, using a simplex search method. First, the highly porous PBA revetment shall be discussed. In Figure 13 the results based on a re-analysis of the wire gauge measurements (and visual inspection of the video data, where necessary) are compared to a smooth impermeable slope. The data of all 33 experiments for Model B and Model C is represented by the blue and red dots, respectively, and the fitted curves are shown in analogous colors.

The corresponding parameters for Model $B\left(\gamma_{p}=0.55\right.$ and $\left.A=1.38\right)$ and Model $C\left(\gamma_{p}=0.52\right.$ and $A=1.41)$ are almost identical with a tendency of slightly less run-up for Model $C$. This tendency can also be observed from the measurement data and the related curves and might have been expected as the highly permeable revetment and filter layer for Model $C$ is $10 \mathrm{~cm}$ thicker than that for Model B (cf. Figure 2). Compared to the impermeable slope, represented by the black curve, a significant reduction of run-up due to porosity is obvious. From the parameters it can be quantified that run-up decreases to almost $50 \%$ for small run-up and still to about $75 \%$ for higher run-up.

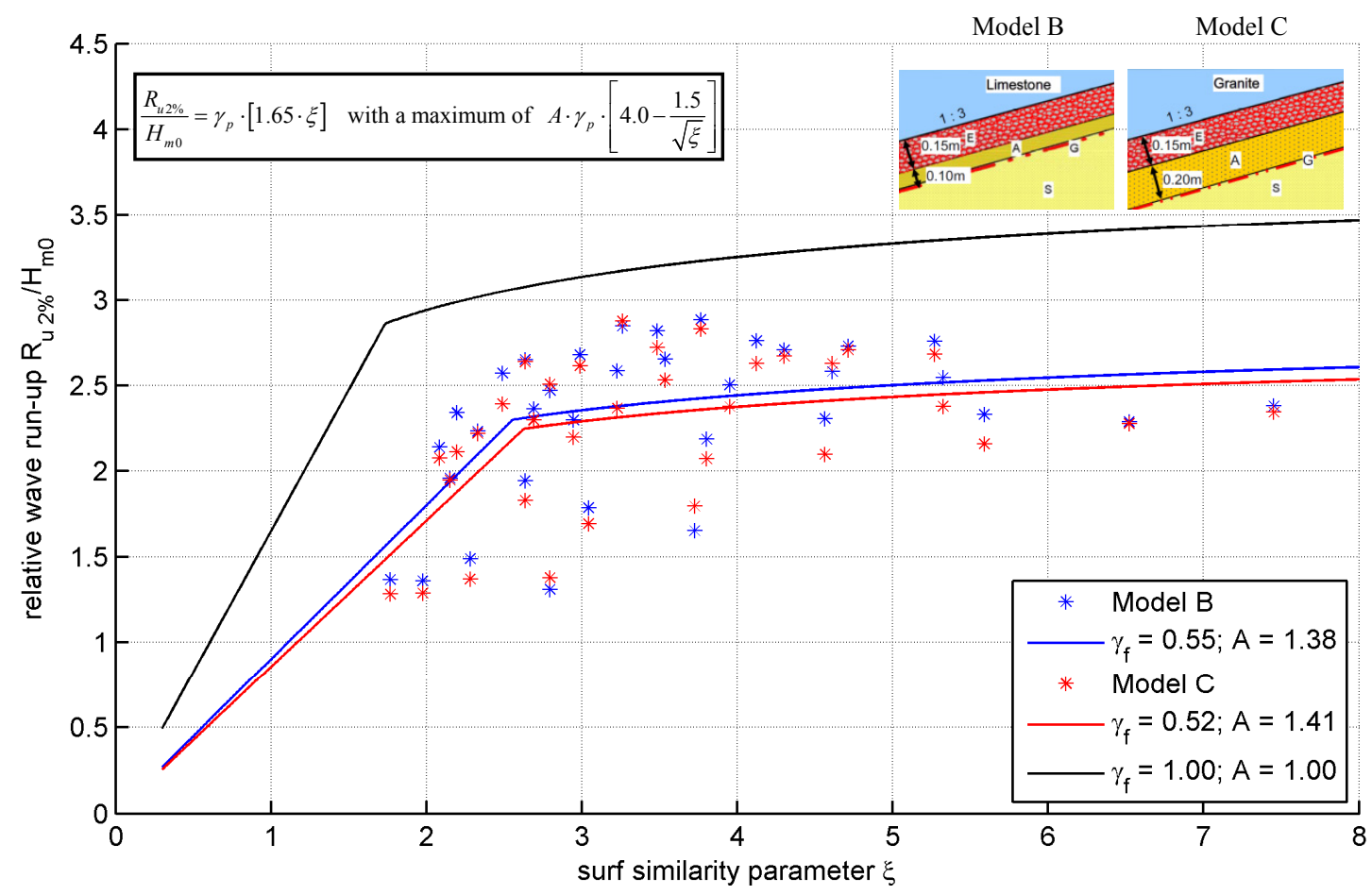

Figure 13. Relative wave run-up $R_{\mathrm{u}, 2 \%} / H_{\mathrm{m} 0}$ for highly porous PBA revetment. Results from re-analysis of runup gauges compared to a smooth impermeable slope represented by the black curve. Blue and red dots are measurement data for Model B and Model C, respectively, and the corresponding curves represent the parameterization according to eq. (3).

A similar plot like Figure 13 and the same results were already presented in Oumeraci et al. (2010 \& 2012), however in a slightly different way. Therefore, the results have been shown and discussed again in order to be consistent with the present approach and for direct comparison with the corresponding results based on the new automated analysis of the video data by timestack image processing, which are discussed in the following.

Figure 14 shows the present results from the video data analysis in comparison to a smooth impermeable slope, represented again by the black curve while the present data is shown in blue and red as above. 


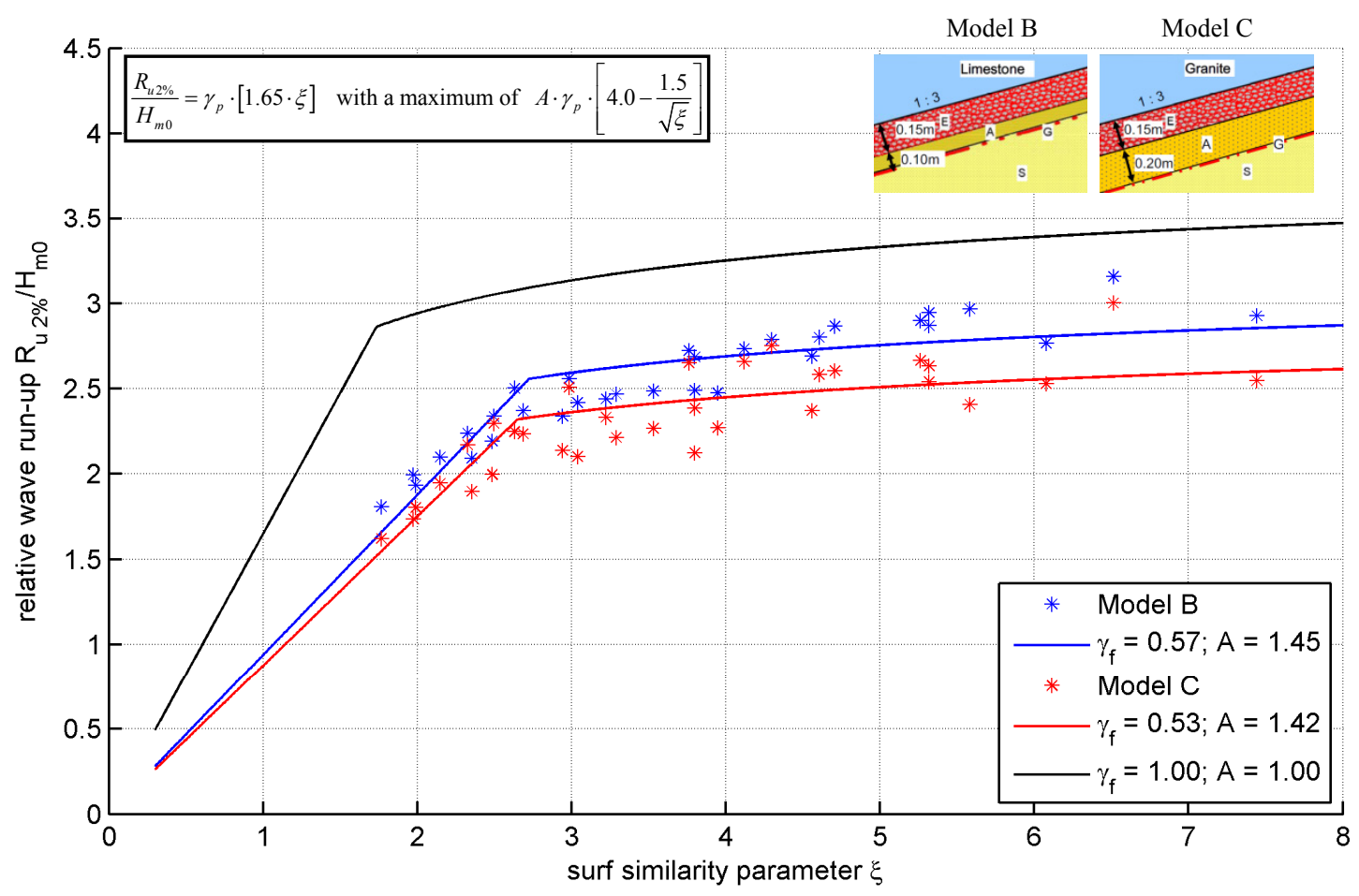

Figure 14. Relative wave run-up $R_{\mathrm{u}, 2 \%} / H_{\mathrm{m} 0}$ for highly porous PBA revetment. Results from present video data analysis compared to a smooth impermeable slope represented by the black curve. Blue and red dots are measurement data for Model B and Model C, respectively, and the corresponding curves represent the parameterization according to eq. (3).

At first sight it is obvious from the dots that the relative run-up values determined from the video data analysis show significantly less spreading than those based on the run-up gauges and partly manual video data analysis in Figure 13 above. This even more enhances the confidence in the reliability of the presented video data analysis and the credebility of the corresponding results.

The tendency of Model $C$ to give slightly lower run-up values is somewhat more pronounced in the results from video data analysis than already observed above for the run-up gauges. This assures that this is obviously a real physical phenomenon due to the larger permeable layer thickness rather than a systematic measurement error. In general the difference between Model B and Model C can be deduced best from the blue and red curves and the corresponding parameters, which in this case are $\gamma_{p}=0.57$ and $A=1.45$ for Model $B$ and $\gamma_{p}=0.53$ and $A=1.42$ for Model $C$. Although in Figure 14 the scatter in the data is much less than that in Figure 13 these values compare astonishingly well to those found by Oumeraci et al. (2010) and presented again above. This confirms that a porous revetment can significantly reduce wave run-up heights and it shows that both measurement techniques are actually well suited for run-up measurements, although the video data analysis based on timestack image processing seems to be slightly more reliable.

This gives further confidence in the following results from the analysis of the IPPB experiments, which is completely based on the video data. As mentioned before the range of the surf-similarity parameter was rather limited (cf. Figure 10) and therefore the data base is actually not perfectly suited to determine the parameters to account for porosity as shown above. However, the curve fit through the data based on equation (3) gave reasonable results. Figure 15 presents the relative wave run-up $R_{\mathrm{u}, 2 \%} / H_{\mathrm{m} 0}$ for each of the four tests series in which the different revetment blocks were directly compared to each other; (a) Conventional vs. IPPB std., (b) IPPB std. vs. IPPB por., (c) IPPB std. vs. $I P P B \bmod 18$ and (d) $I P P B \bmod 18$ vs. $I P P B \bmod 25$. It is apparent that compared to a smooth impermeable slope, represented by the black curve all tested stones show lower run-up heights, even if the effect is expectedly less pronounced than for the highly permeable PBA revetment above. However, from the accumulated scattering of the measurement data, represented by the blue and red dots, it is evident, that a parameterization based on this data surely contains some uncertainties. 

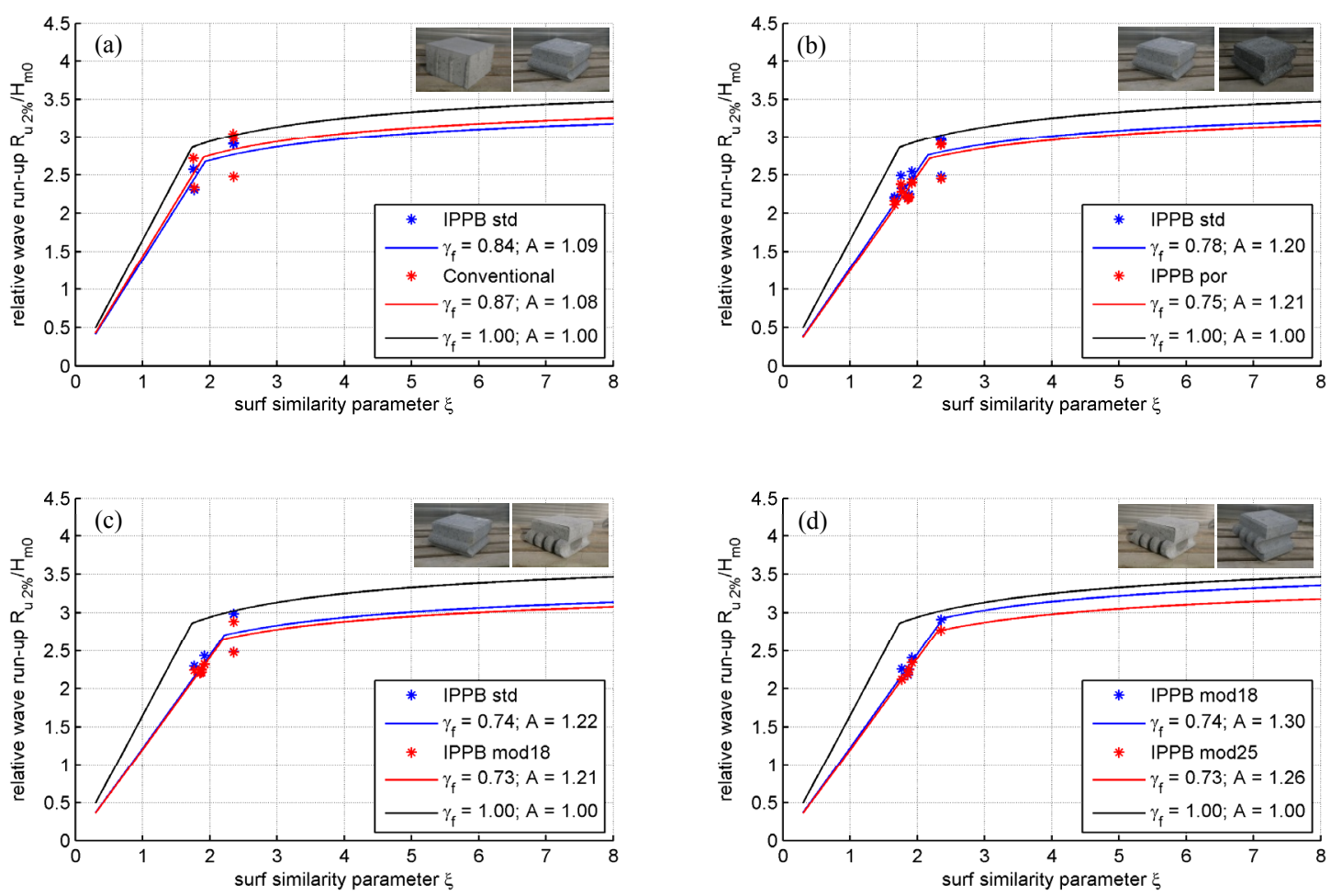

Figure 15. Relative wave run-up $R_{\mathrm{u}, 2 \%} / H_{\mathrm{m} 0}$ for weakly „porous“ IPPB revetment. Results from present video data analysis compared to a smooth impermeable slope (black curve). The individual panels show the results from all four test series: (a) Conventional vs. IPPB std., (b) IPPB std. vs. IPPB por., (c) IPPB std. vs. IPPB mod18 and (d) IPPB mod18 vs. IPPB mod25.

This uncertainty is also reflected in the parameters $\gamma_{p}$ and $A$, which are displayed in the legend of each plot. Although the waves for each of the tests series were more or less identical, the run-up data and the corresponding parameters are different. While for IPPB modl8 in panel (c) and (d) the difference is yet small, it is quite considerable for $I P P B$ std. comparing panel (a), (b) and (c).

If those differences are averaged by considering the data for the different revetment blocks without separating into the four test series, the result for the IPPB experiments become even clearer, as presented in Figure 16. Still all tested revetment blocks show less run-up than a smooth impermeable slope, but now the difference between the Conventional stone and the IPPB stones is more evident. Due to the slot and key system the gap between the individual interlocked stones is bigger compared to the non-interlocked Conventional stone and in consequence the permeability ("porosity") is higher, leading to slightly less run-up. Also an intercomparison between the individual $I P P B$ stones shows the expected tendency with decreasing run-up from IPPB std. over IPPB por. to IPPB modl18 and IPPB $\bmod 25$, even if the differences are very small and actually fall within the uncertainty of the data and the parameterization.

As for the latter reason it is not useful to distinguish between the individual IPPB stones, but rather treat them together, resulting in one parameterization for this kind of weakly „porous“ revetment with $\gamma_{p}=0.76$ and $A=1.21$. Analogously for the PBA revetment it is not distinguished between the different set-ups Model B and Model C, but all data is treated together, resulting in parameters $\gamma_{p}=0.55$ and $A=1.43$ for this highly porous revetment. Both parameterizations are finally compared to a smooth impermeable slope $\left(\gamma_{p}=1.00\right.$ and $\left.A=1.00\right)$ in Figure 17. The effect of porosity is evident from the curves and can be quantified from the determined parameters to reduce run-up by about $10 \%$ up to $24 \%$ for the weakly "porous" IPPB revetment and more than $20 \%$ up to $45 \%$ for the highly porous PBA revetment. Not only because the IPPB revetment is actually not porous and the data set for these experiments was limited, it is not attempted to look for a relation between those results and the porosity of the revetment. The numbers should therefore only be taken as to indicate the quite remarkable effect of porosity on wave run-up, however, still more research is needed to approve and extent the current results and make them applicable in practice. 


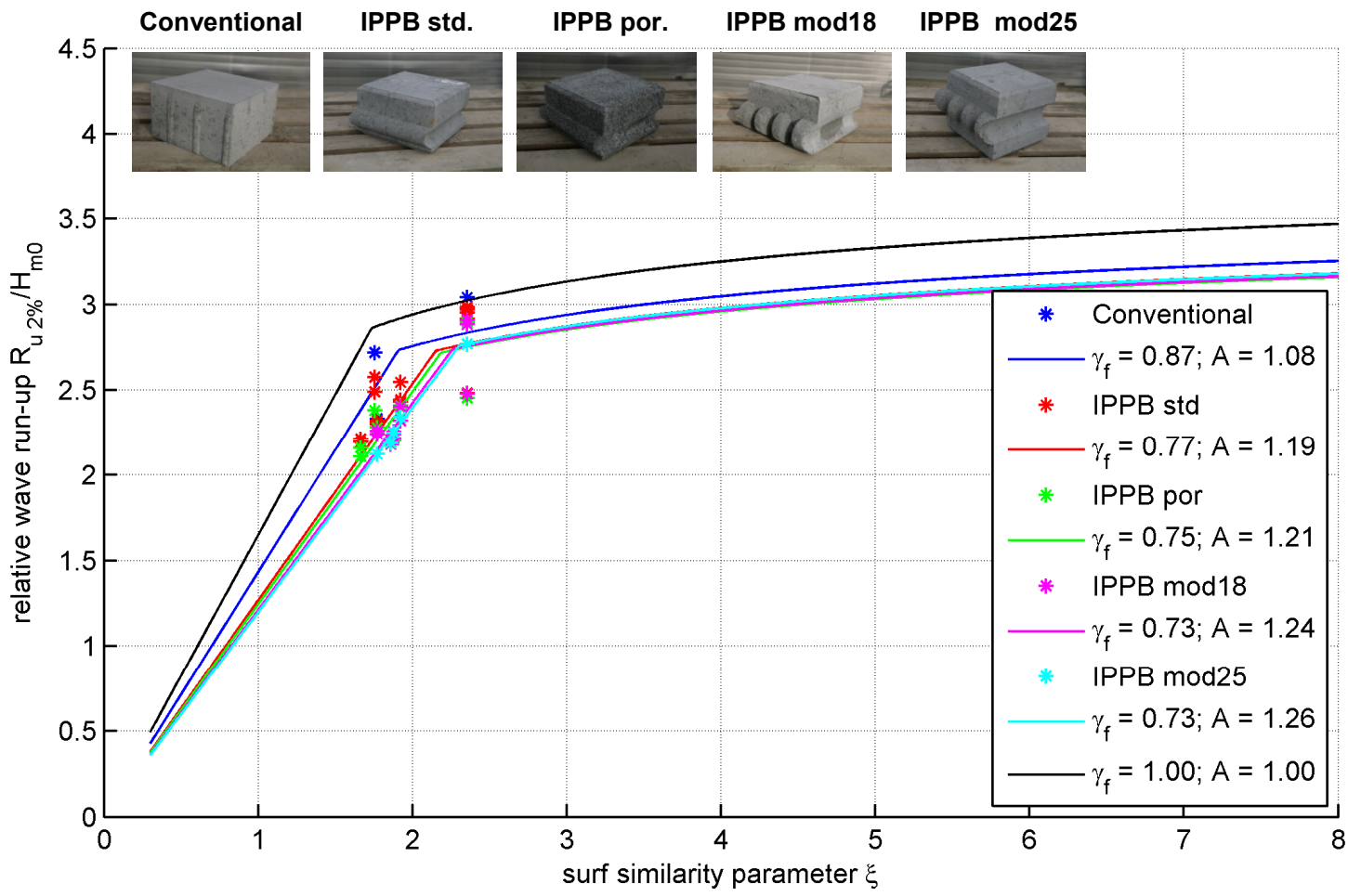

Figure 16. Relative wave run-up $R_{\mathrm{u}, 2 \%} / H_{\mathrm{m} 0}$ for weakly "porous" IPPB revetment. Results from present video data analysis compared to a smooth impermeable slope (black curve). Blue and red dots are measurement data for Model B and Model C, respectively, and the corresponding curves represent the parameterization according to eq. (3)

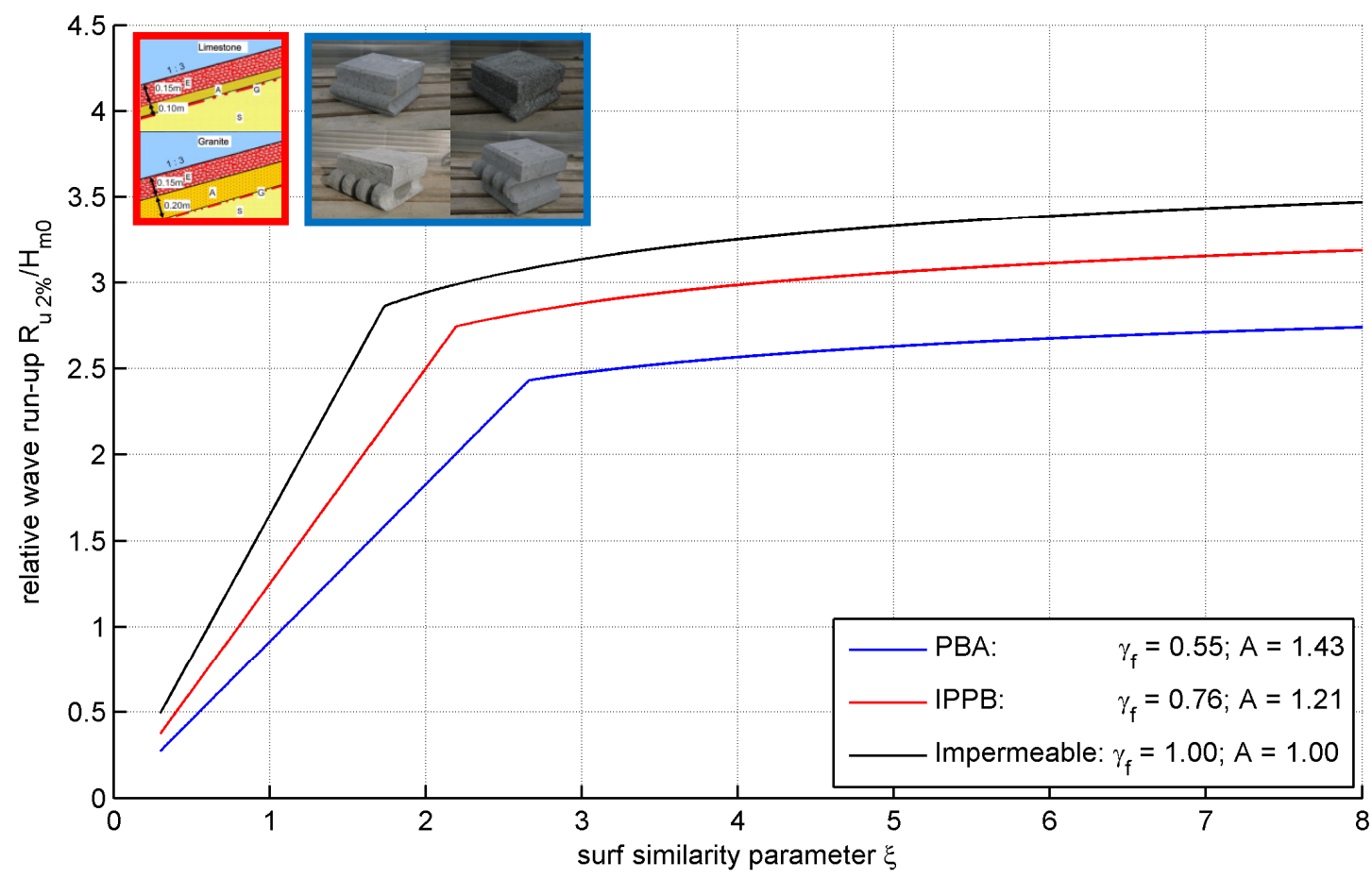

Figure 17. Comparison of wave run-up parameterizations for porous revetments. Black curve: smooth impermeable slope, red curve: weakly "porous" IPPB revetment, blue curve: highly porous PBA revetment. 


\section{CONCLUSIONS}

The effect of porosity on wave run-up has been investigated by re-analyzing the data from large scale model tests performed in GWK on two types of revetments. The PBA revetment tests were focused on the hydraulic performance of a new type of highly porous revetment made of polyurethane bonded aggregates and in the IPPB revetment tests the stability of an interlocked pattern placed concrete block revetment was tested. The IPPB revetment has a porosity of ca. $3 \%$ due to the gaps between the individual concrete blocks and is considered as smooth and weakly "porous" for the present study, while the effect of the roughness of the highly porous PBA revetment on wave run up is assumed to be negligible due to the small sizes of the aggregates $(16 / 36 \mathrm{~mm})$.

The video footage taken during the experiments was originally intended only for documentation and visual analysis. Therefore only commercial CCD cameras were used and the set-up was not optimized for automatic image processing. However, the quality was sufficient to obtain timestack images along predefined transects, which after some enhancements provided time series of shore line excursion, which could be evaluated for run-up statistics using an open access GUI software developed in Matlab ${ }^{\circledR}$ (https://sourceforge.net/projects/guitimestack).

The wave run-up time series from the new video data analysis have been compared to those directly measured with wave run-up gauges (PBA revetment tests only). It could be shown that the general agreement was satisfactory and even more some obvious issues with the upper of the two runup gauges could be identified and quantified. In a previous analysis of the data (Oumeraci et al., 2010 $\& 2012$ ) those issue were already realized as well and in those cases in which the upper gauge was active the $R_{\mathrm{u}, 2 \%}$ run-up had to be determined from visual analysis of the video footage.

A parameterization to account for the effect of porosity was suggested by applying the commonly used run-up formula given in EuroTop (2007). The parameters $\gamma_{p}$ and $A$ were determined by curve fitting through the data, which covered a range for the surf-similarity parameter of $1.77<\xi<7.44$ for the PBA revetment tests and $1.67<\xi<2.35$ for the IPPB revetment tests. Even if the latter range was limited, the curve fitting provided reasonable results, showing less run-up for the weakly "porous" interlocked revetment compared to a smooth impermeable slope. An intercomparison between the different revetment block types showed only little differences within the uncertainty of the data. Therefore all data for the IPPB revetment tests were put together resulting in parameters $\gamma_{p}=0.76$ and $A=1.21$, which are considered to be representative for this type of weakly "porous" revetment.

For the highly porous PBA revetment tests both the run-up gauges and the video data were analyzed for run-up. Although the $R_{\mathrm{u}, 2 \%}$ values from the run-up gauges showed significantly more scatter than those from the video data analysis, the derived parameters were very similar, showing slightly less run-up for Model C compared to Model $B$ due to the $10 \mathrm{~cm}$ thicker filter layer. Even if the uncertainty of the parameterization was much less and the distinction between the two different revetment set-ups more significant than for the IPPB revetment, the data was treated together resulting in parameters $\gamma_{p}=0.55$ and $A=1.43$ for this type of highly porous revetment.

Taking the two parameterizations found for the present cases and comparing with a smooth impermeable slope $\left(\gamma_{p}=1.00\right.$ and $\left.A=1.00\right)$ the effect of porosity could be clearly identified and quantified to reduce the relative run-up $R_{\mathrm{u}, 2 \%} / H_{\mathrm{m} 0}$ run-up by about $10 \%$ up to $24 \%$ for the weakly "porous" IPPB revetment and more than $20 \%$ up to $45 \%$ for the highly porous PBA revetment. The design height of a coastal defense structure depends on the highest run-up occurring for the highest surf-similarity parameter, therefore only the lower reduction values are decisive for design purposes, i.e. a dike with a porous revetment could be about $10 \%$ to $20 \%$ lower than a comparable dike with an impermeable revetment.

Summing up it may be concluded that the presented video data analysis based on timestack images is a robust and reliable technique for measuring wave run-up and probably even superior to conventional wire gauges. The effect of porosity in reducing run-up on a slope could also be demonstrated to be quite significant for the present cases. Therefore the presented results can be seen as a first step into the right direction and it seems definitely worth to follow this approach and to push more research efforts in investigating the positive effects of porous revetments more comprehensively.

\section{ACKNOWLEDGMENTS}

The authors gratefully acknowledge the support of BASF Polyurethanes $\mathrm{GmbH}$ for funding the PBA revetment experiments and Berding Beton GmbH for funding the IPPB revetment experiments. Our thanks also go to Prof. Holger Schüttrumpf of RWTH Aachen for his efforts in reviewing the paper and last but not least we would like to express our appreciation for all the interesting questions and valuable comments on the presentation held at the conference. 


\section{REFERENCES}

Aagaard, T., Holm, D., 1989. Digitization of wave runup using video records. Journal of Coastal Research, 5, pp. 547-551.

Battjes, J.A., 1974. Surf similarity. Proceedings of 14th International Conference on Coastal Engineering (ICCE), Copenhagen, Denmark, ASCE, pp. 466-480.

EuroTop (2007) European Overtopping Manual edited by Pullen, T., Allsop, N.W.H., Bruce, T., Kortenhaus, A., Schüttrumpf, H., Van der Meer, J.W.; Die Küste, Heft 73, Kuratorium für Forschung im Küsteningenieurwesen. www.overtopping-manual.com.

Gier, F., H. Schüttrumpf, J. Mönnich, Van der Meer. J., 2012. Stability of interlocked pattern placed block revetments. Proceedings $33^{\text {rd }}$ International Conference on Coastal Engineering. (ICCE), Santander, Spain, ASCE.

Holman, R.A., 1986. Extreme value statistics for wave run-up on a natural beach. Coastal Engineering, 9, pp. 527-544.

Hunt, I.A., 1959. Design of seawalls and breakwaters. J. Waterw. Harb. Div. ASCE, 85 (WW3), pp. $123-152$.

Iribarren, C.R., Nogales, C., 1949. Protection des ports. Proceedings of $17^{\text {th }}$ International Navigation Congress, Lisbon, Portugal.

Liebisch, S., J.C. Alcérreca Huerta, A. Kortenhaus, H. Oumeraci. 2012. Bonded porous revetments Effect of porosity on wave-induced loads and hydraulic performance, Proceedings of $33^{\text {rd }}$ International Conference on Coastal Engineering (ICCE), Santander, Spain, ASCE.

Mase, H., 1989. Random Wave Runup Height on Gentle Slope. Journal of Waterway, Harbors Division, ASCE, 115 (5), pp. 649-661.

Nielsen, P., 1989. Wave setup and runup: An integrated approach. Coastal Engineering, 13 (1), pp. 1-9.

Otsu, N., 1979. A threshold selection method from gray-level histograms. IEEE Trans. Syst. Man. Cybern, 9, pp. 62-66.

Oumeraci, H., Staal, T., Pfoertner, S., Ludwigs, G., Kudella, M., 2010. Hydraulic Performance, Wave Loading and Response of Elastocoast Revetments and their Foundation - A Large Scale Model Study. Berichte Leichtweiß-Institut für Wasserbau, Technische Universität Braunschweig, Nr. 988, Braunschweig, Germany.

Oumeraci, H., Staal, T., Pförtner, S., Ludwigs, G., 2012. Hydraulic performance, wave loading and response of PBA revetments and their foundations. European Journal of Environmental and Civil Engineering, pp. 1-28

Ruggiero, P., Holman, R.A., Beach, R.A., 2004. Wave run-up on a high-energy dissipative beach. Journal of Geophysical Research, 109 (C06025).

Stockdon, H. F., Holman, R. A., Howd, P. A., Sallenger, J. A. H., 2006. Empirical parameterization of setup, swash, and runup. Coastal Engineering, 53 (7), pp. 573-588.

Synolakis, C.E., 1987. The run-up of solitary waves. Journal of Fluid Mechanics, 185, pp. 523-555.

Vousdoukas, M.I., Velegrakis, A.F., Dimou, K., Zervakis, V., Conley, D.C., 2009. Wave run-up observations in microtidal, sediment-starved pocket beaches of the Eastern Mediterranean. Journal of Marine Systems, 78 (Supplement 1), S37-S47.

Vousdoukas, M. I., Wziatek, D., Almeida, L. P., 2012. Coastal vulnerability assessment based on video wave run-up observations at a meso-tidal, reflective beach. Ocean Dynamics, 62 (1), pp. 123-137. 